\title{
Peter Waterman and T-matrix methods
}

\author{
M.I. Mishchenko ${ }^{\mathrm{a}}$, P.A. Martin ${ }^{\mathrm{b}, *}$ \\ a NASA Goddard Institute for Space Studies, 2880 Broadway, New York, NY 10025, USA \\ b Department of Applied Mathematics and Statistics, Colorado School of Mines, Golden, CO 80401, USA
}

\section{A R T I C L E I N F O}

Article history:

Received 13 October 2012

Accepted 30 October 2012

Available online 9 November 2012

Keywords:

Acoustic scattering

Electromagnetic scattering

Elastodynamic scattering

Discrete random media

Extended boundary condition method

$T$-matrix

Superposition $T$-matrix method

Radiative transfer

\begin{abstract}
A B S T R A C T
This paper summarizes the scientific legacy of Peter C. Waterman (1928-2012) who introduced concepts and theoretical techniques that have had a major impact on the fields of scattering by particles and particle groups, optical particle characterization, radiative transfer, and remote sensing. A biographical sketch is also included.
\end{abstract}

(c) 2012 Elsevier Ltd. All rights reserved.

\section{Introduction}

At a wedding reception in 1998, Peter Waterman, feeling shy in an unfamiliar crowd, approached the only well recognizable figure in the room: an old, grand piano. Without meaning to, he became the entertainment of the night, playing original scores for the guests, filling the air with graceful energy. After the reception, the hotel manager followed Peter and his wife Karen into the elevator and asked if Peter would be interested in a job playing the piano at the hotel. Peter looked at Karen, smiled, and politely refused. Although music was an essential part of his life, his professional allegiance was to mathematical physics.

A quiet and unassuming man of habits, Peter Cary Waterman (Fig. 1) was well known to many but personally acquainted with a few. During his more than 50 years in science, he had (co)authored only 39 peer-reviewed

\footnotetext{
* Corresponding author. Tel.: +1 3032733895.

E-mail addresses: michael.i.mishchenko@nasa.gov (M.I. Mishchenko), pamartin@mines.edu (P.A. Martin).
}

publications; these are listed below in Section 8 and cited as [Wxx]. Yet his research has had a dramatic and longlasting impact and to a large degree has guided the progress in the disciplines of electromagnetic, acoustic, and elastic wave scattering by obstacles.

\section{Early years}

Born in Albany, New York, on 14 June 1928 to Frederick Collins and Gertrude Melissa (Cary) Waterman, Peter Waterman graduated from Bethlehem High School, Delmar, New York, in 1946 (Fig. 2). He received a BS degree in physics from Syracuse University in 1951, and from 1952 to 1953, served as a physics instructor at Union College in Schenectady, New York. Waterman was subsequently appointed to an Alcoa Research Fellowship in the Division of Applied Mathematics at Brown University. There, his first few papers [W02, W03, W04, W06] and his MS thesis [W01] were studies of elastic wave propagation through anisotropic materials.

In 1954, Peter Waterman married Katherine Adella Dearstyne, with whom he had three sons: Diedrich, Jonathan, and Jeremy. Peter and Katherine divorced in 1975. 


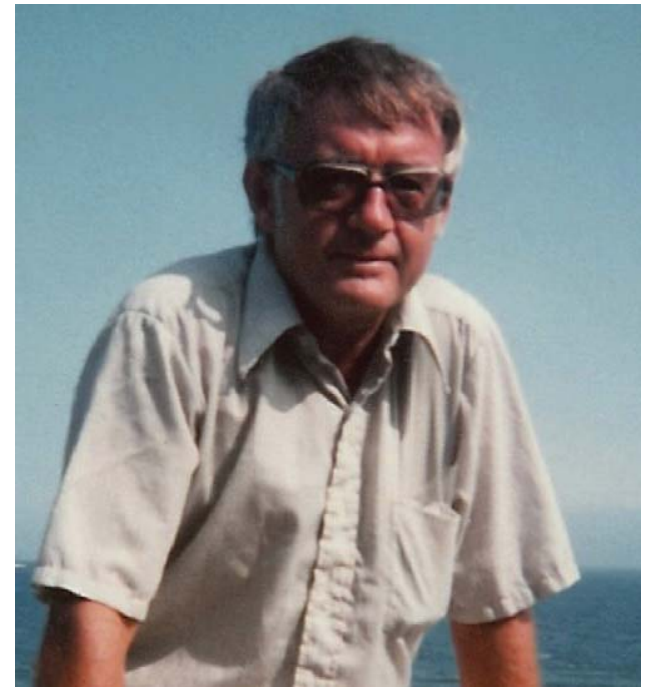

Fig. 1. Peter Cary Waterman (1928-2012).

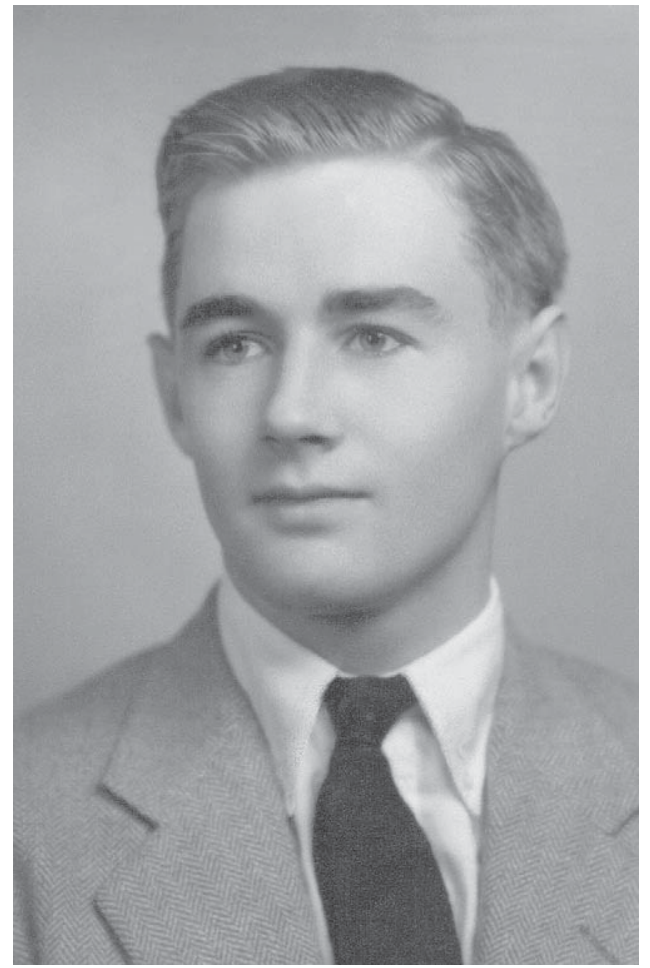

Fig. 2. Peter Waterman, a 1946 graduate of Bethlehem High School, Delmar, New York.

Waterman received his $\mathrm{PhD}$ degree in applied mathematics from Brown in 1958. His thesis on "Multiple scattering of waves" [W05] was supervised by Rohn Truell. This work will be discussed in Section 3.

After graduation, Waterman worked briefly for the Linde Company (1958), in Tonawanda, New York. There, he investigated the unmixing of gases in Laval nozzles, leading to two papers [W07, W08].

\section{Multiple scattering}

From 1959 to 1965, Waterman worked in the Research and Advanced Development Division of the Avco Corporation in Wilmington, Massachusetts. He extended his thesis work with Truell on three-dimensional acoustic scattering (governed by the Helmholtz equation, $\left(\nabla^{2}+k^{2}\right) u=0, k$ being the wavenumber and $u$ the acoustic field) by random arrangements of identical spherical obstacles, in the spirit of earlier work by Leslie Foldy and Melvin Lax. The main result is a formula for the effective wavenumber, $K$, assuming that the number of scatterers per unit volume, $n$, is small. Waterman and Truell [W09] obtained the formula

$(K / k)^{2}=\left[1+2 \pi n k^{-2} f(0)\right]^{2}-\left[2 \pi n k^{-2} f(\pi)\right]^{2}$,

where $f(\theta)$ is the far-field pattern for scattering of a plane wave by a single sphere. (The scattered field is asymptotically $r^{-1} \mathrm{e}^{\mathrm{i} k r} f(\theta)$ as $r \rightarrow \infty$, where $r$ and $\theta$ are spherical polar coordinates.) Written out, Eq. (1) becomes

$K^{2}=k^{2}+4 n \pi f(0)+n^{2} \delta_{2}$,

where

$\delta_{2}=(2 \pi / k)^{2}\left\{[f(0)]^{2}-[f(\pi)]^{2}\right\}$.

The term proportional to $n$ in Eq. (2) is well known. The second-order coefficient, $\delta_{2}$, had been obtained by Urick and Ament [1] using a very different argument: the attraction of Waterman and Truell's derivation is that it is systematic, with testable assumptions, and that it has the potential for extension to other physical situations (such as electromagnetic scattering). In fact, it turned out later that the formula for $\delta_{2}$, Eq. (3), is wrong: for a review and references, see Ref. [2]. Nevertheless, the paper [W09] has been very influential: it has been cited about 500 times and it was reprinted in 1996 in the SPIE Milestone volume on "Selected papers on linear optical composite materials," edited by Akhlesh Lakhtakia.

John Fikioris joined Avco in 1962. He graduated from Harvard University in 1963 with a PhD thesis on "The theory of radially stratified media," written under Ronold W. P. King's direction. Fikioris and Waterman [W12] improved and corrected the analysis in Ref. [W09]. They also wrote [W12, p. 1414]:

The vector extension of the present work has been performed, in application to the electromagnetic case. The procedure and results of this extension will be described in a subsequent paper.

That paper did not appear until 2013 [W42]. For a description of how this came about, see Section 7.

\section{The extended boundary condition}

In 1965, Waterman published a paper [W13] on electromagnetic scattering by a perfectly conducting obstacle in which he introduced the "extended boundary condition". He was interested in developing a numerical method for three-dimensional obstacles of arbitrary shape, one that does not suffer from spurious irregular frequencies. He describes his formulation as follows: 
The induced surface currents on the obstacle must produce a field that, through interference, precisely cancels the incident wave throughout the interior volume. Employing this statement as a boundary condition leads to an "extended" integral equation, defined to be one in which the unknown (surface current) appears in an integral over the surface, whereas the equation itself is required to hold throughout the volume bounded by that surface. ... Mathematical tractability of the extended integral equation stems from the observation that one need only make the field vanish in any portion of the interior volume. The field can then be shown to vanish everywhere in the interior [by analytic continuation].

The portion chosen is a ball, and vector spherical wavefunctions (VSWFs) are introduced leading to a linear algebraic system which is truncated and solved numerically. Results for scattering by an axisymmetric spherecone-sphere shape are presented and compared with experimental results obtained by N.E. Pedersen. (Waterman would work with Norman and Jeanne Pedersen for 40 years.) The extension to dielectric scatterers was presented at the 1968 URSI Symposium on electromagnetic theory in Stresa, Italy [W14].

Waterman's 1965 paper [W13] includes some remarks on computational aspects:

One present drawback of the method is the poor numerical convergence of the truncation procedure which has been found when dealing with more elongated shapes. This is of course not surprising, since one is departing from the nearly spherical shapes most ideally suited to the vector wave functions employed.

This difficulty provoked many further investigations by Waterman and others.

\section{The $T$-matrix}

From 1965 to 1975, Waterman worked for the MITRE Corporation in Bedford, Massachusetts. His first journal publication from this period [W15] introduces the transition matrix $T$ in the context of acoustic scattering. This infinite matrix is defined by $c=T d$, where the column vector $c$ contains the coefficients in an expansion of the scattered field in terms of outgoing spherical wavefunctions and the column vector $d$ contains the coefficients in an expansion of the incident field in terms of regular spherical wavefunctions. Waterman emphasizes that "what is more important" with his new approach is that it "works directly with the transition matrix, in which setting the rôle of reciprocity and energy conservation is explicitly displayed." He relates $T$ to the scattering matrix $S$ by $S=I+2 T$, where $I$ is the unit matrix, and thereby infers properties of $T$ from those of $S$. He shows that the $T$-matrix can be built by adapting his earlier use of the extended boundary condition (Section 4); the result is the formula $Q T=-\operatorname{Re}(Q)$, where the matrix $Q$ contains the values of certain surface integrals involving spherical wavefunctions. He gives a detailed investigation of the structure of $Q$ and shows that $Q$ is symmetric for ellipsoidal scatterers. Finally, he presents some numerical results. (For a detailed description of acoustic $T$-matrix theory, see chapter 7 of Ref. [3].)

Waterman extended his acoustic formulation [W15] to electromagnetic scattering in his famous 1971 paper [W16]. This classic paper and its predecessor [W13] have been cited more than a thousand times. Both were reprinted in the 1988 SPIE Milestone volume, "Selected papers on light scattering," edited by Milton Kerker.

In the 1970s, Waterman developed T-matrix methods for other situations, including elastodynamic problems [W21] and grating problems (scattering by periodic surfaces) [W20]. Other groups also began using T-matrix methods. Then, in June 1979, Vijay and Vasundara Varadan hosted at The Ohio State University a major international symposium on the $T$-matrix method attended by 125 participants, including Peter Waterman. The proceedings [4] were published (Waterman contributed a survey article [W24]); the preface includes these words:

A major development in the last ten years has been the T-Matrix method. This method which incorporates certain elegant analytical properties has also proven to be an efficient computational technique. ... The Symposium was focused on the $T$-Matrix so that its full potential and/or limitations could be properly understood in the context of other well known methods ...

Several databases of peer-reviewed publications advancing, based on, or using the $T$-matrix method stand as a vivid testimony to the great importance of Waterman's contribution. The first was published in 1988 and lists 151 publications on various aspects of electromagnetic, acoustic, and elastic wave scattering [5]. A more recent database initiated in 2004 [6] and supplemented by regular updates (the most recent, Ref. [7], is included in this special issue) has a much narrower scope and covers only electromagnetic scattering by finite objects. Yet it includes over 1800 references. Besides the edited collection [4], Waterman's work on the T-matrix method and the theory of multiple scattering is central to many other books; see, for example, Ref. [3] and Refs. [8-12].

\section{Later activities}

From 1975 to 1990, Waterman was a consulting physicist, primarily for Digital Equipment and Panametrics, Inc. He also taught a graduate-level course on "New techniques for wave propagation problems with irregular boundaries" at Northeastern University. During the fall of 1980 , he held a visiting professorship at the Institute of Theoretical Physics in Göteborg, Sweden, where he worked closely with Staffan Ström and Gerhard Kristensson (Fig. 3).

The paper [W26], published in 1981, appears to be a digression from Waterman's main course of research. However, it turned out to be a very useful mathematical account of the standard plane-parallel problem of the scalar radiative transfer theory. As with many of Waterman's journal publications, Ref. [W26] was rooted in the applied-physics work that he had done as a consultant. 


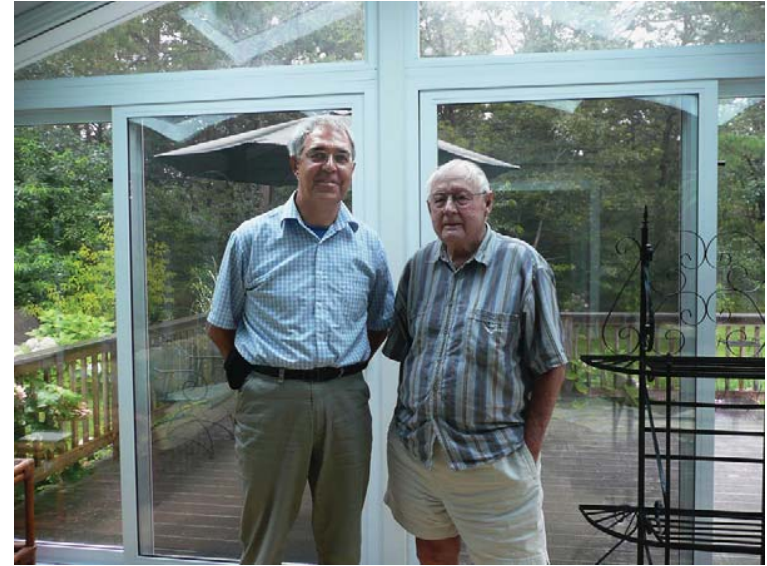

Fig. 3. Gerhard Kristensson visiting Peter Waterman in 2008 (West Yarmoth, MA). Courtesy of G. Kristensson.

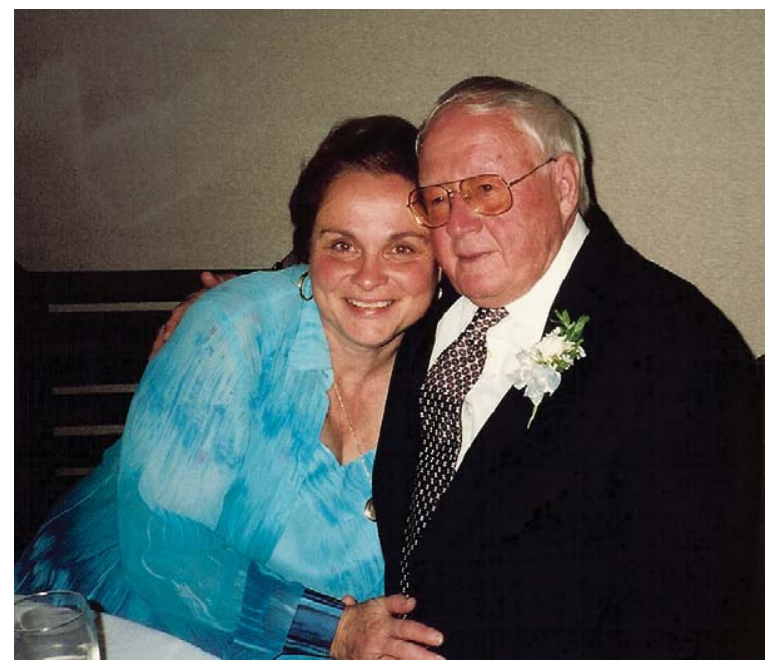

Fig. 4. Karen and Peter Waterman had a common ancestor, Edward Doty, who came to America in 1620 on the Mayflower. Doty was born in Suffolk, England in 1598 and died in Plymouth, MA in 1655. The picture was taken in October 1999 at Jonathan Waterman's wedding.

The result was an elegant formulation based on the matrix-operator technique and new analytical solutions for the reflection and transmission matrices in the limiting cases of infinitesimal or effectively infinite optical thickness of the scattering layer.

From 1990 through 2000, Waterman was employed by Pedersen Research, Inc., continuing to work in the area of electromagnetic and acoustic scattering. For example, he wrote several papers with Jeanne Pedersen on scattering by thin wires [W33, W35, W36].

In 1996, Peter married Karen Marlene Gates (Fig. 4), with whom he lived happily in West Yarmouth, Massachusetts, until his peaceful death on 3 June 2012. His last paper [W41] was submitted in July 2008 at the age of 80 .

Peter Waterman was a member of Sigma Xi, Sigma Pi Sigma, Pi Mu Epsilon, the American Physical Society, and
A BEAT NOTE ISOLATOR FOR USE IN PIANO TUNING

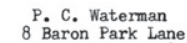

8. Baron Park Lane
Burlington, MA 01803

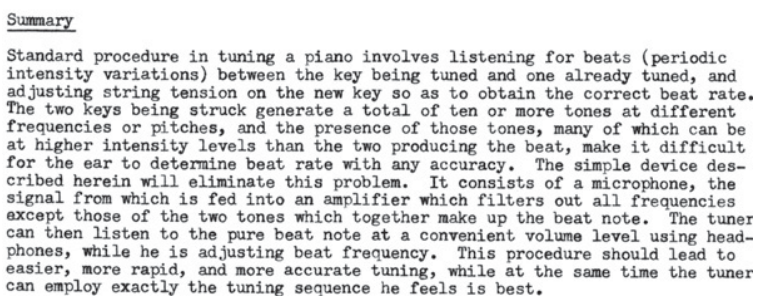

Fig. 5. Summary of an unpublished manuscript on piano tuning.

the Electromagnetics Academy. He was on the technical program committee for the joint URSI/IEEE International Symposium several times and chaired the sessions on numerical methods and electromagnetic theory.

While Waterman was active in his career, consulting for the US Army as a mathematical physicist into his 80s, he was also an accomplished pianist and an amateur composer. His research in piano tuning and tempering resulted in several unpublished manuscripts (Fig. 5) as well as a US patent, awarded to him in 1981 [W25]. Peter Waterman's music was recorded and later played during his memorial service on 12 June 2012.

\section{Multiple scattering of waves. III}

To conclude this brief account of Peter Waterman's life and accomplishments, it is appropriate to provide some background material on Ref. [W42] included in this special issue. This paper dates back to 1964 . The manuscript was found in Waterman's professional archive on 1 July 2012 along with printouts of several e-mail messages exchanged by Waterman and John Fikioris in the fall of 2010. Although it remains unknown why this finalized manuscript had remained unpublished, the likely explanation is Waterman's move from Avco to the MITRE Corporation in 1965 and his new interest in the extended boundary condition method. In one of his e-mails of 2010, Fikioris suggested the idea of publishing the 1964 manuscript, perhaps with minor updates. Waterman embraced the idea and suggested developing a plan of actions within two months. Unfortunately, it appears that this was not done as no traces of subsequent correspondence between Waterman and Fikioris have been found. John Fikioris died on 14 February 2012. Peter Waterman died on 3 June 2012.

Given the absence of further information, we decided to leave the 1964 manuscript in its present form. One of us (PAM) has re-typeset the manuscript in LATEX and made a few minor edits, mostly intended to comply with the JQSRT format and style.

The "new" paper is the third in a three-part series. The first was published in 1961 [W09]. It has the same title as Waterman's PhD thesis of 1958 [W05]. Fikioris and Waterman published the second part in 1964 [W12]. Both papers are concerned with scalar wave problems (acoustic scattering by random configurations of many identical spheres) but Fikioris and Waterman did state that they had also made the extension to electromagnetic scattering 
problems: the paper describing that extension remained unpublished until now.

At the heart of the analysis in the third part [W42] is an exact treatment of electromagnetic scattering by many spheres, combining separated Lorenz-Mie solutions in terms of VSWFs with appropriate addition theorems. For VSWFs, such addition theorems were not available until Cruzan's paper from 1962 [13]. Interestingly, Fikioris and Waterman appear to be the first to find the notorious minus sign error in Ref. [13]. The 1964 manuscript has a handwritten note by Fikioris indicating that Cruzan had acknowledged this error in a letter sent to Fikioris and Waterman.

Ref. [W42] essentially describes what is now known as the superposition $T$-matrix method $[8,9]$ or the generalized Mie theory [14]. It thus anticipates Refs. [15,16] and all numerous reinventions and modifications of this technique which is now used routinely to solve the problem of electromagnetic scattering by many spheres.

\section{Publications by P.C. Waterman}

[W01] Waterman PC. The effect of orientation on planewave propagation in single crystals. MS thesis, Brown University, 1956.

[W02] Waterman PC, Teutonico LJ. Ultrasonic double refraction in single crystals. J Appl Phys 1957; 28:266-70.

[W03] Espinola RP, Waterman PC. Ultrasonic interferometer for the measurement of the temperature dependence of elastic constants. J Appl Phys 1958; 29:718-21.

[W04] Waterman PC. Orientation dependence of ultrasonic attenuation in zinc. J Appl Phys 1958;29:1190-5.

[W05] Waterman PC. Multiple scattering of waves. PhD thesis, Brown University; 1958.

[W06] Waterman PC. Orientation dependence of elastic waves in single crystals. Phys Rev 1959;113: 1240-53.

[W07] Waterman PC, Stern SA. Separation of gas mixtures in a supersonic jet. J Chem Phys 1959;31: 405-19.

[W08] Stern SA, Waterman PC, Sinclair TF. Separation of gas mixtures in a supersonic jet. II. Behavior of helium-argon mixtures and evidence of shock separation. J Chem Phys 1960;33:805-13.

[W09] Waterman PC, Truell R. Multiple scattering of waves. J Math Phys 1961;2:512-37. Reprinted in: Lakhtakia A, editor. Selected papers on linear optical composite materials (SPIE Milestone series, vol. MS120). Bellingham, WA: SPIE Press; 1996. p. 475-500.

[W10] Waterman PC. Roots of Legendre functions of variable index. J Math \& Phys 1963;42:323-8.

[W11] Waterman PC, Yos JM, Abodeely RJ. Numerical integration of non-analytic functions. J Math \& Phys 1964;43:45-50.

[W12] Fikioris JG, Waterman PC. Multiple scattering of waves. II. "Hole corrections" in the scalar case. J Math Phys 1964;5:1413-20.
[W13] Waterman PC. Matrix formulation of electromagnetic scattering. Proc IEEE 1965;53:805-12. Reprinted in: Kerker $M$, editor. Selected papers on light scattering (SPIE Milestone series, vol. 951). Bellingham, WA: SPIE Press; 1988. p. 803-10.

[W14] Waterman PC. Scattering by dielectric obstacles. Alta Frequenza 1969;38:348-52.

[W15] Waterman PC. New formulation of acoustic scattering. J Acoust Soc Am 1969;45:1417-29.

[W16] Waterman PC. Symmetry, unitarity, and geometry in electromagnetic scattering. Phys Rev D 1971;3: 825-39. Reprinted in: Kerker M, editor. Selected papers on light scattering (SPIE Milestone series, vol. 951). Bellingham, WA: SPIE Press; 1988. p. 811-25.

[W17] Waterman PC. Numerical solution of electromagnetic scattering problems. In: Mittra $\mathrm{R}$, editor. Computer techniques for electromagnetics. Oxford: Pergamon Press; 1973. p. 97-157.

[W18] Waterman PC. Energy conservation and WKB methods. Am J Phys 1973;41:373-88.

[W19] Waterman PC, Tomljanovich NM. Virtual pulse effect in incoherent scattering. IEEE Trans Antennas Propag 1974;22:275-8.

[W20] Waterman PC. Scattering by periodic surfaces. J Acoust Soc Am 1975;57:791-802.

[W21] Waterman PC. Matrix theory of elastic wave scattering. J Acoust Soc Am 1976;60:567-80.

[W22] Waterman PC. Matrix theory of elastic wave scattering. II. A new conservation law. J Acoust Soc Am 1978;63:1320-5.

[W23] Waterman PC. Matrix methods in potential theory and electromagnetic scattering. J Appl Phys 1979;50: 4550-66.

[W24] Waterman PC. Survey of T-matrix methods and surface field representations. In: Varadan VK, Varadan VV, editors. Acoustic, electromagnetic and elastic wave scattering-focus on the $T$-matrix approach. New York: Pergamon Press; 1980. p. 61-78.

[W25] Waterman PC. Method and apparatus for piano tuning and tempering. US patent 4,253,374 (March 3, 1981).

[W26] Waterman PC. Matrix-exponential description of radiative transfer. J Opt Soc Am 1981;71:410-22.

[W27] Kristensson G, Waterman PC. The $T$ matrix for acoustic and electromagnetic scattering by circular disks. J Acoust Soc Am 1982;72:1612-25.

[W28] Waterman PC. Analytical consequences of the extended boundary condition. Wave Motion 1983;5: 273-95.

[W29] Waterman PC. Surface fields in potential theory and acoustic scattering. J Acoust Soc Am 1984;76: 1215-26.

[W30] Waterman PC. Comments on "Comparison of the $T$-matrix and Helmholtz integral equation methods for wave scattering calculations" [J Acoust Soc Am 1985;77:369-374]. J Acoust Soc Am 1985;78:804.

[W31] Waterman PC, Pedersen NE. Electromagnetic scattering by periodic arrays of particles. J Appl Phys 1986;59:2609-18. 
[W32] Bruce CW, Ashmore DR, Pittman PC, Pedersen NE, Pedersen JC, Waterman PC. Attenuation at a wavelength of $0.86 \mathrm{~cm}$ due to fibrous aerosols. Appl Phys Lett 1990;56:791-2.

[W33] Waterman PC, Pedersen JC. Scattering by finite wires. J Appl Phys 1992;72:349-59.

[W34] Bruce CW, Jelinek AV, Halonen RM, Stehling MJ, Pedersen JC, Waterman PC. Millimeter wavelength attenuation efficiencies of fibrous aerosols. J Appl Phys 1993;74:3688-91.

[W35] Waterman PC, Pedersen JC. Electromagnetic scattering and absorption by finite wires. J Appl Phys 1995;78:656-67.

[W36] Waterman PC, Pedersen JC. Scattering by finite wires of arbitrary $\epsilon, \mu$, and $\sigma$. J Opt Soc Am A 1998; 15:174-84.

[W37] Waterman PC. Surface fields and the $T$ matrix. J Opt Soc Am A 1999;16:2968-77.

[W38] Waterman PC, Pedersen JC. Isotropic scattering by penetrable cylinders. J Opt Soc Am A 2000;17: 740-44.

[W39] Waterman PC. Scattering, absorption, and extinction by thin fibers. J Opt Soc Am A 2005;22:2430-41.

[W40] Waterman PC. The T-matrix revisited. J Opt Soc Am A 2007;24:2257-67.

[W41] Waterman PC. T-matrix methods in acoustic scattering. J Acoust Soc Am 2009;125:42-51.

[W42] Fikioris JG, Waterman PC. Multiple scattering of waves. III. The electromagnetic case. J Quant Spectrosc Radiat Transfer http://dx.doi.org/10.1016/j. jqsrt.2012.09.007, this issue

\section{Acknowledgments}

We thank Karen Waterman and George Fikioris for generous help and fine cooperation. We also thank them for granting the permission to publish in JQSRT the 1964 manuscript by John Fikioris and Peter Waterman.

\section{References}

[1] Urick RJ, Ament WS. The propagation of sound in composite media. J Acoust Soc Am 1949;21:115-9.

[2] Linton CM, Martin PA. Multiple scattering by multiple spheres: a new proof of the Lloyd-Berry formula for the effective wavenumber. SIAM J Appl Math 2006:66:1649-68.

[3] Martin PA. Multiple scattering. Interaction of time-harmonic waves with $N$ obstacles. Cambridge: Cambridge University Press; 2006.

[4] Varadan VK, Varadan VV, editors. Acoustic, electromagnetic and elastic wave scattering-focus on the T-matrix approach. New York: Pergamon Press; 1980.

[5] Varadan VV, Lakhtakia A, Varadan VK. Comments on recent criticism of the T-matrix method. J Acoust Soc Am 1988;84:2280-4.

[6] Mishchenko MI, Videen G, Babenko VA, Khlebtsov NG, Wriedt Th. $T$-matrix theory of electromagnetic scattering by particles and its applications: a comprehensive reference database. J Quant Spectrosc Radiat Transfer 2004;88:357-406.

[7] Mishchenko MI, Khlebtsov NG, Videen G, Wriedt Th, Zakharova NT. Comprehensive T-matrix reference database: a 2011-2012 update. J Quant Spectrosc Radiat Transfer, this issue.

[8] Tsang L, Kong JA, Shin RT. Theory of microwave remote sensing. New York: Wiley; 1985.

[9] Mishchenko MI, Travis LD, Lacis AA. Scattering, absorption, and emission of light by small particles. Cambridge: Cambridge University Press; 2002.

[10] Borghese F, Denti P, Saija R. Scattering from model nonspherical particles. Theory and applications to environmental physics. Berlin: Springer; 2003.

[11] Doicu A, Wriedt T, Eremin YuA. Light scattering by systems of particles. Null-field method with discrete sources-theory and programs. Berlin: Springer; 2006.

[12] Mishchenko MI, Travis LD, Lacis AA. Multiple scattering of light by particles. Radiative transfer and coherent backscattering. Cambridge: Cambridge University Press; 2006.

[13] Cruzan OR. Translational addition theorems for spherical vector wave functions. Q Appl Math 1962;20:33-40.

[14] Quinten M. Optical properties of nanoparticle systems: Mie and beyond. Weinheim: Wiley-VCH; 2011.

[15] Bruning JH, Lo YT. Multiple scattering of EM waves by spheres, part I-Multipole expansion and ray-optical solutions. IEEE Trans Antennas Propag 1971;19:378-90.

[16] Bruning JH, Lo YT. Multiple scattering of EM waves by spheres, part II-numerical and experimental results. IEEE Trans Antennas Propag 1971;19:391-400. 